\title{
El pensamiento simbólico de los habitantes de La Florida (Quito-Ecuador)
}

La pensée simbolique des habitants de La Florida (Quito-Équateur)

The symbolic thought of the La Florida's people (Quito-Ecuador)

\section{María del Carmen Molestina Zaldumbide}

\section{(2) OpenEdition}

\section{Journals}

Edición electrónica

URL: http://journals.openedition.org/bifea/3931

DOI: 10.4000/bifea.3931

ISSN: 2076-5827

Editor

Institut Français d'Études Andines

Edición impresa

Fecha de publicación: 1 diciembre 2006

Paginación: 377-395

ISSN: 0303-7495

Referencia electrónica

María del Carmen Molestina Zaldumbide, «El pensamiento simbólico de los habitantes de La Florida (Quito-Ecuador) », Bulletin de l'Institut français d'études andines [En línea], 35 (3) | 2006, Publicado el 01 junio 2007, consultado el 01 diciembre 2020. URL : http://journals.openedition.org/bifea/3931 ; DOI https://doi.org/10.4000/bifea.3931

\section{(c) $(1)$}

Les contenus du Bulletin de l'Institut français d'études andines sont mis à disposition selon les termes de la licence Creative Commons Attribution - Pas d'Utilisation Commerciale - Pas de Modification 4.0 International. 


\title{
El pensamiento simbólico de los habitantes de La Florida (Quito-Ecuador)
}

\author{
María del Carmen Molestina Zaldumbide*
}

\section{Resumen}

Las excavaciones en la Necrópolis del Yacimiento de la Florida (Quito, Ecuador) han arrojado una serie de datos sobre el pensamiento fúnebre de sus habitantes durante el Periodo de Integración. La cronología temprana demuestra que la cultura Negativo del Carchi o Capulí se extiende desde La Florida hacia el Norte. Sepulturas similares se han estudiado en la zona de Otón (Pichincha), el Carchi y Nariño (Colombia).

Palabras clave: arqueología, sepulturas, Periodo de Integración del Ecuador

\section{La pensée simbolique des habitants de La Florida (Quito-Équateur)}

\section{Résumé}

Les excavations dans la Necrópolis de la Florida à Quito-Équateur, ont apporté de information, en relation avec la mort, l'idéologie de ses habitants au cours de la Période d'intégration. Pendant cette période, la culture Negativo del Carchi aussi appelée Capulí, s'est répandue dans le territoire de La Florida et vers le Nord de ce territoire. Des sépultures similaires ont été étudiées dans la zone d'Otón, El Carchi et Nariño (Colombie).

Mots clés : archéologie, tombeau, Période d'Integration de L'Équateur 


\title{
The symbolic thought of the La Florida's people (Quito-Ecuador)
}

\begin{abstract}
Excavations in the necropolis of the archaeological site of La Florida (Quito, Ecuador) has produced evidence of the funeral practices of its inhabitants during the Integration Period. The early chronology of the site demonstrates that the culture of Negativo del Carchi or Capuli extends from the La Florida site to the north. Similar tombs have been studied in the Otón zone (Pichincha), in Carchi Province, and Nariño (Colombia).
\end{abstract}

Key words: archaeology, tombs, Ecuadorian Integration Period

\section{INTRODUCCIÓN}

La zona objeto de esta investigación corresponde a la Meseta de Quito en la Provincia de Pichincha-Ecuador y más concretamente al Distrito Metropolitano de Quito. La Meseta de Quito forma parte de La Hoya del Guayllabamba. Al norte, limita con el nudo de Mojanda-Cajas y al sur por el de Tiopullo, al oeste el Pichincha que forma parte de la Cordillera Occidental y que a su vez está constituida por tres elevaciones volcánicas: el Guagua Pichincha, el Rucu Pichincha y el Cóndor Guachana. Al este se encuentran los volcanes Cayambe, cerro Puntas, Ilaló, Antisana y Cotopaxi y al oeste los valles de Cumbayá, Tumbaco, Los Chillos y Machachi.

Desde el punto de vista geológico el vulcanismo de origen cuaternario propio del callejón interandino dio como resultado la formación de cangahua y sedimentos fluvio-lacustres que rellenan grandes depresiones como la cuenca de Quito-Guayllabamba y que ha modelado el paisaje característico de la Sierra ecuatoriana (Alvarado Cevallos, 1996: 9).

La ciudad de San Francisco de Quito está situada en la parte más angosta de la Meseta y en las estribaciones del Macizo del Pichincha. Limita hacia el este con una serie de lomas como Puengasí, Guanguiltagua e Itchimbía que se hallan separadas por quebradas producto del sistema de fallas del callejón interandino. Hacia el sur se extiende hasta el sector de Tambillo y al norte hacia Pomasqui-San Antonio. Su terreno es irregular con altitudes que van desde los 2850 a los 3100 m.s.n.m. (IGM, 1992: 6). Presenta una serie de drenajes provenientes del Pichincha y Atacazo, siendo el más importante el río Machangara y su afluente el río Grande que corre de sur a norte, además de algunas quebradas profundas con arroyos intermitentes que pueden presentar crecidas durante el invierno, algunas llevan el agua que baja del Pichincha hacia el Este. La mayoría de estas arrastran oro, piritas y calcopiritas aluviales (Alvarado Cevallos, 1966: 11).

En la ciudad de San Francisco de Quito existen zonas lacustres que forman pequeños pantanos y que tuvieron gran importancia en la época prehispánica para la obtención de totora, hematites, peces y aves e incluso para la agricultura en camellones, como se ha demostrado en varias investigaciones (Knapp \& Ryder, 1985).

En la zona urbana de la Y, el Aeropuerto y la Jipijapa los suelos están formados por arcillas, limos y arenas con pómez que corresponden a depósitos lacustres y volcánicos, los que dan origen a la laguna de Iñaquito (actual aeropuerto).

La geología del la Meseta condicionó los asentamientos prehispánicos en las laderas del Macizo del Pichincha y su aprovechamiento agrícola. Sus habitantes ocuparon las planicies inundadas desarrollando una tecnología agrícola de camellones como los que se han localizado cerca de los sitios habitacionales de Chillogallo e Iñaquito en el área urbana de la ciudad. 
El Anónimo de 1573 y Rodríguez de Aguayo (1571) reafirman las evidencias arqueológicas tanto de los asentamientos urbanos como de las zonas de cultivo e indican que los indígenas cultivaban en los camellones maíz y papas, base de la dieta prehispánica.

El uso de la tierra desarrolló una tecnología agrícola, urbana y ceremonial que se evidencia tanto en las narraciones del siglo XVI y XVII como en las investigaciones arqueológicas.

La ubicación de los poblados en las laderas del Macizo del Pichincha facilitó no solo el acceso a las tierras de cultivo no inundadas sino también al agua de las abundantes quebradas y a la cacería en los bosques aledaños. Las quebradas durante el verano y una vez secas, se utilizarían como caminos para el comercio hacia todos los puntos cardinales. De ellas obtendrían oro aluvial, pirita y calcopirita así como otras piedras duras para la elaboración de objetos de orfebrería y líticos. Las montañas pasarían a formar parte importante del pensamiento religioso de sus habitantes. No es gratuito que encontremos en las sepulturas de La Florida a los difuntos orientados hacia el Pichincha.

Para el Periodo de Integración los asentamientos registrados son: Chillogallo, Chilibulo, Rumipamba, Chaupicruz y La Florida, que ocupan una buena parte de las laderas occidentales del Macizo del Pichincha. Sus manifestaciones materiales guardan gran semejanza entre sí, por lo que podríamos afirmar que se trata de un mismo grupo étnico. Las particularidades geográficas y geológicas de la Meseta de Quito dieron como consecuencia toda una serie de asentamientos humanos interrelacionados y a la vez autónomos tanto económica como políticamente.

\section{EL YACIMIENTO DE LA FLORIDA}

Se encuentra en las laderas del Pichincha, entre los 2900 y 3000 metros sobre el nivel del mar, hacia el costado noroccidental de la ciudad de San Francisco de Quito, entre las quebradas La Pulida y San Juan, en el sector denominado San Vicente en el barrio de La Florida.

Las características topográficas permiten ubicarlo dentro de la zona de vida de transición entre bosque húmedo Montano Bajo y de bosque muy húmedo Montano Bajo con temperaturas medias anuales de $12^{\circ}$ a $18^{\circ} \mathrm{C}$ y precipitaciones anuales entre 500 y $1000 \mathrm{~mm}$. La vegetación está constituida por matorrales que se localizan en las quebradas o barrancos, bosques de eucaliptos, pastos y cultivos, paisaje que en relación con la época prehispánica se halla muy alterado (Cañadas Cruz, 1980: 20).

Gran parte de la zona se ha urbanizado y con ello los vestigios prehispánicos han desaparecido, queda sin embargo un pequeño sector libre de construcciones, donde sería posible realizar investigaciones arqueológicas.

Desde que se descubrió el lugar en 1983, se han realizado varias investigaciones aisladas, que han dado como resultado una visión muy fragmentada dejando muchas incógnitas difíciles de resolver y en muchos casos insalvables.

El yacimiento estuvo ocupado desde el Formativo, Camino \& Castillo (1997: 19) registran sepulturas individuales con esqueletos en posición sedente fuertemente flexionados, aparentemente sin ajuar. Este tipo de sepulturas son similares a las de Cotocollao al norte de la ciudad (Villalba, 1988: 101), iniciándose en este periodo temprano con la tradición de enterrar a los individuos de esta manera - costumbre que continúa hasta el Periodo de Integración y que no es única de la Meseta de Quito sino de la Sierra Norte en generalde un asentamiento Formativo en La Florida está corroborada por el hallazgo de vestigios habitacionales. Solorzano (2004) realiza un análisis muy completo de una casa Formativa localizada en el conjunto de edificios Terrana I, cerca de las sepulturas objeto de nuestro estudio. Desgraciadamente tampoco hay una datación absoluta; en ambos casos se hace una correlación relativa de fechas en base al material cultural. 
Solorzano (en estudio) excava en La Florida algunas sepulturas de pozo medio, que posiblemente puedan ubicarse en Desarrollo Regional. Hay que esperar los resultados de estas investigaciones para establecer correlaciones cronológicas con respecto a las fechas hasta ahora obtenidas.

Doyon (1989: 142) excava 6 sepulturas de pozo profundo con cámara central, de entierros múltiples, cuya datación las sitúan en 340 y 420 a.C., fecha que se ha puesto en duda debido al tipo de cerámica procedente de los ajuares funerarios.

A fin de estudiar el pensamiento fúnebre de los habitantes de La Florida en el periodo de Integración realizamos excavaciones de tres sepulturas de pozo profundo y cámara central y una de pozo poco profundo, en el sector contiguo a las sepulturas excavadas por Doyon. Se trata de enterramientos múltiples con un promedio de 16 individuos por sepultura. La de pozo poco profundo es individual. Las dataciones hasta ahora obtenidas las localizan en el Periodo de Integración Temprano (600 a 680 d.C.) en el caso de las de pozo profundo y cámara central, mientras que la de pozo poco profundo pertenece al final del Periodo de Integración (1505 d.C.).

Son estructuras circulares con entierros múltiples, los esqueletos se depositaron en posición sedente fuertemente flexionada, algunas directamente en el suelo y otros sobre tiangas. Existen evidencias de estas sepulturas en Cangahua (Jijón y Caamaño, 1920: 5), el Carchi (Grijalva, 1937: 166; Larrea, 1972: 106), Nariño (Uribe, 1977-1978: 67) y Otón (Aguilera, 2006: com. pers.), por lo que se podría afirmar que se trata de una tradición constructiva propia de la Sierra Norte. Llama la atención que en el resto del territorio no se hayan descubierto estas estructuras, lo que se explica por estar a más de $2 \mathrm{~m}$ bajo el nivel actual del terreno, esto dificulta los hallazgos casuales. En todo caso es una incógnita difícil de resolver por el momento.

El sistema constructivo de las sepulturas de pozo profundo y cámara central refleja una sociedad compleja en la que la distribución del trabajo debió estar muy regulada. La temporada invernal en que excavaron las tres sepulturas estudiadas indica que se dedicaba a estas actividades un periodo del año en el que ya se había culminado con las labores agrícolas y en el que el comercio a larga distancia, debido a las fuertes lluvias, era imposible, lo que debió producir excedente de mano de obra. El que se construyeran en esta época del año tiene además una razón tecnológica, la cangahua mojada es más fácil de trabajar. Por las inclemencias del tiempo, desde el inicio de su excavación estas debieron estar cubiertas a fin de evitar su inundación. Nosotros aún no hemos encontrado vestigios de estas cubiertas, sin embargo Camino \& Castillo (1997:30) encontraron sepulturas en cuyo entorno había huecos de poste.

Evidencias para la Sierra Norte de bohíos con sepulturas en su interior nos proporcionan para Huaca y Cuasmal, Max Uhle (1928:30), González Suárez y los cronistas de los siglos XVI y XVII. Se ha establecido que los pastos y otros grupos étnicos solían enterrarse en sus casas ya que estas en cuanto a su construcción eran similares a las habitacionales. Miño Grijalva (1977: 172) al analizar las diferentes investigaciones realizadas en el Carchi interpreta los bohíos como únicamente funerarios. Para Max Uhle, los cementerios son las aglomeraciones de bohíos en cuyo centro se encuentra una especie de plaza y cerca de esta se ubican los bohíos más grandes, que localiza en Cuasmal y Chitanque son cementerios. Los bohíos habitacionales se encuentran más bien alineados en las costillas de los cerros (Uribe, 1977-1978: 67). Los bohíos descritos para el Carchi y Nariño fueron de planta circular y paredes de tierra apisonada con techumbre de paja. Para sujetar las paredes y techumbre se colocaron en el piso postes espaciados y entre las paredes.

El sistema constructivo empleado en las sepulturas denota un gran conocimiento de la geología. Excavar una sepultura de $15 \mathrm{~m}$ promedio de profundidad requirió de una inversión energética bastante elevada, teniendo en cuenta que los instrumentos utilizados fueron unos palos puntiagudos posiblemente de madera de un tamaño no mayor a $45 \mathrm{~cm}$ de largo, a juzgar por las huellas que dejaron en las paredes, con los cuales aflojaban la tierra y hachas de mano con las que iban dando la forma a la sepultura. El trabajo pues requirió de especialistas con un buen conocimiento no solo de los materiales sino también de su comportamiento, la forma circular no solo es dada por la ideología sino también por la tecnología, por lo que el tiempo/hombre que se debió emplear es considerable. 
Las sepulturas se fueron excavando en varias etapas. Dependiendo de la disponibilidad de mano de obra especializada se pudo trabajar en una o dos estructuras simultáneamente. Al comparar la tecnología de la sepultura 1 con la 2, con una diferencia temporal de 50 años en su utilización, se aprecia un desarrollo tecnológico de la segunda con relación a la primera.

La más antigua (630 d.C.) presenta desgaste en el sector sureste, indicio de que tanto individuos como objetos bajaban y subían arrastrándose por la pared, utilizando posiblemente algún tipo de polea. En la más tardía (680 d.C.) es posible el uso de una escalera de cuerdas, debido a que en el tramo sureste se han labrado apoyos a manera de escalones para facilitar la bajada y subida tanto de personas como de objetos. El cálculo del círculo de las sepulturas también se ha perfeccionado, llegando a obtener una circunferencia casi perfecta. En cuanto a las paredes, las dos sepulturas mantienen la misma forma de trabajo y tallado. La sepultura 4 (600 d.C.) presenta únicamente huellas verticales producto de la excavación, demostrándose también un avance en las técnicas de construcción con relación a las sepulturas más modernas.

Ateniéndonos a la forma de las sepulturas vemos que no importa el periodo en que fueron construidas, todas son circulares, lo que no solo es propio del yacimiento de La Florida sino que se extiende a la Meseta de Quito y a la Sierra Norte en general. Posiblemente esto no es solo un resultado tecnológico, sino que también, existe una simbología relacionada con el círculo. El diámetro y profundidad del pozo de estas sepulturas no tiene una mayor variación temporal, al contrario de lo que sucede con la distribución de sus elementos.

Las sepulturas de pozo profundo y cámara central en el yacimiento de La Florida culminan en una plataforma de aproximadamente $70 \mathrm{~cm}$ de ancho, que da paso a la cámara central constituida por un pozo de profundidad variable. En la sepultura 1, la mayor profundidad la tiene el pozo, siendo en la 2 y 4 más cortos; en éstas, la cámara central tiene una mayor profundidad, diferencia que da como resultado un mejor aprovechamiento del espacio. La sepultura 4 no tiene plataforma, por lo que el uso de una plataforma para las sepulturas 1 y 2 indica un mayor aprovechamiento de la estructura constructiva para alojar mayor cantidad de individuos.

En la cámara central de las sepulturas 1 y 4 todos los individuos se enterraron directamente en el piso, mientras que en la sepultura 2 se habían colocado uno encima del otro, de esta manera pudieron enterrar a cinco individuos adultos con ajuares individualizados, los de la cámara central de la sepultura 1 solo fueron 3 adultos y un infante, el ajuar fue muy pobre y parece que fue compartido por todos los individuos; los de la sepultura 4 fueron 3 con ajuares individualizados.

La disposición de los cadáveres en general da cuenta de que los individuos fueron enterrados en distintas épocas, conforme se fue dando su deceso. No hemos encontrado huellas de una muerte ritual como describe León Doyon, todos fallecieron de muerte natural (León, 2004-2005). La evidencia arqueológica indica que fueron colocados ya sea en el suelo de la sepultura o en tiangas y luego fueron cubiertos con tierra agrícola. Cuando la sepultura se llenó, se procedió al sellamiento paulatino; cada cierto tiempo visitaban a los difuntos, realizaban sus ceremonias al interior de la sepultura y luego cubrían el espacio con tierra. En el relleno del pozo cada metro — aproximadamente - presenta un pequeño apisonamiento producto del peso de las personas que realizaron las ceremonias en la sepultura. De esta forma fueron cubriéndolo con tierra agrícola hasta que una vez sellado retiraron la estructura del bohío, y cubrieron la superficie con la misma tierra agrícola formando un túmulo, quedando a la vista un montículo de aproximadamente $3 \mathrm{~m}$ de altura. Con el paso del tiempo, la erosión y las labores agrícolas acumularon tierra en los espacios entre montículos y luego sobre estos, por ello el piso actual no deja ver estas estructuras.

Según el Anónimo de Quito (1573: 215) a los entierros acudía una muchedumbre que acompañaba al difunto con llanto y bailes, acompasados por la música. Antonio de Borja (1591: 483) cuenta que, cuando los indígenas de Pimapiro (Imbabura) enterraban a sus muertos encendían fogatas y quemaban hierbas para evitar que el muerto regrese, a la vez que brindaban con chicha. 
El fuego debió estar presente en las ceremonias, encontramos vasijas con restos de hollín. En cada uno de los apisonados del relleno de las sepulturas se desprendió un fuerte olor a hollín, indicios que corroborarían la presencia del fuego en las ceremonias.

Oberem (1981) reporta montículos funerarios en Cochasqui, se trata de sepulturas con pozo de aproximadamente $5 \mathrm{~m}$ de profundidad con entierros individuales. Si bien son posteriores a los nuestros, tienen relación con La Florida.

Existe un cambio en las ceremonias fúnebres, en la sepultura 1, parece que el ajuar no se cubría con tierra después de cada entierro, mientras que en la 2 y 4 , al menos en la cámara central se cubría con tierra tanto al muerto como a su ajuar.

El análisis matricial de las sepulturas 1,2 y 4 demuestra que se inició la construcción de la sepultura 4 para luego desde esta continuar con la construcción de la sepultura 1 (fig. 1). Se ocupó primero la sepultura 4 y luego la 1. La zona con huellas del arrastre de materiales y subida y bajada de las personas se halla a un costado de la abertura que comunica a las dos sepulturas. En la sepultura 4 no hemos encontrado huellas que ubiquen la zona por donde entraban y salían las personas y objetos. Los campos de cultivo posiblemente estuvieron a cargo de los shamanes, quienes debieron tener la autoridad necesaria para disponer de un buen grupo de la población trabajando en ellos. Cerca de la necrópolis en estudio se encontraron unos canales (Terán, 1985) que posiblemente podrían estar relacionados con los campos de cultivo sagrados.

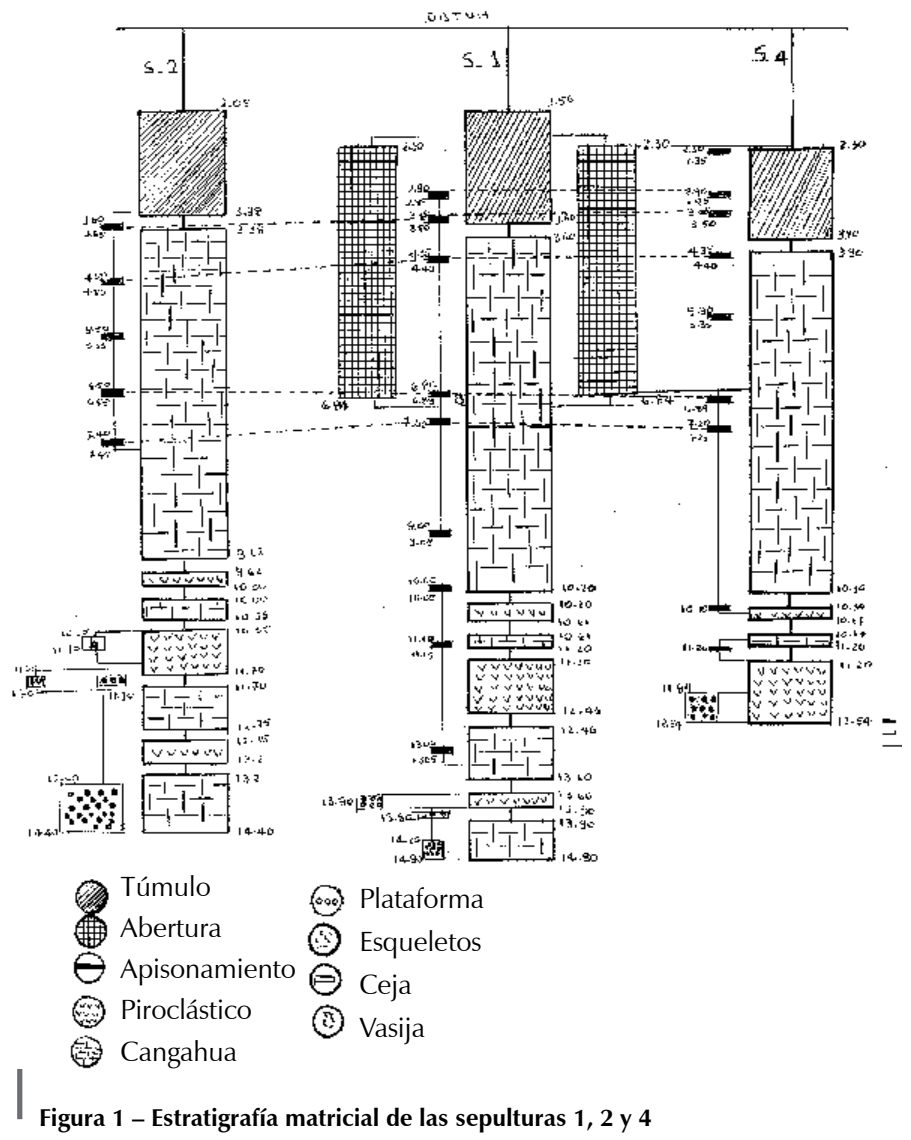


La organización espacial de las sepulturas denota una planificación de la necrópolis predeterminada, no parecería que exista una jerarquización en cuanto a las sepulturas y los rituales fúnebres. La Florida posiblemente fue un centro socioeconómico que trasciende demográfica y productivamente a las sociedades tribales, debiendo existir una organización jerárquica bien determinada que —en lo que tiene que ver con las ceremonias fúnebres— pudo manejar eficientemente a la población.

Es importante la existencia de un lugar central utilizado como eje para los intercambios (de objetos y de información). Estos lugares suelen ser sitios de importancia político religiosa, lo que explicaría la existencia de una necrópolis elaborada y de rituales complejos, evidencia que se ha demostrado.

\section{EL PENSAMIENTO HACIA LA MUERTE}

En todos los grupos sociales se refleja la inquietud por el más allá, desarrollándose toda una filosofía al respecto. Las evidencias se plasman en diferentes estructuras monumentales y en los ajuares y ofrendas, así como en ritos y ceremonias que no siempre dejan huellas tangibles.

El medio ambiente en que vive un determinado grupo humano es importante para su desarrollo tecnológico y filosófico; éste determinará su forma de vida y organización social, así como también las relaciones con los grupos de su entorno.

El Área Septentrional Andina es una zona compleja que se caracteriza por la variedad de nichos ecológicos cercanos entre sí, lo que facilitó el desarrollo y el desenvolvimiento de relaciones comerciales a corta, media y larga distancia y una influencia ideológica mutua, cuyo resultado fáctico es la variedad y similitud en sus manifestaciones culturales.

Las evidencias arqueológicas y los documentos tempranos hablan de sociedades muy complejas que llegan a una estratificación social jerarquizada la misma que se refleja en sus ceremonias fúnebres. Una posible explicación para la profundidad de las sepulturas sería la relación con el agua. Las aguas subterráneas del Pichincha proporcionan una humedad constante. Posiblemente se buscó llegar hasta las aguas profundas para lograr una inmersión de los difuntos en las aguas purificadoras y regeneradoras que proporcionarían la entrada en la vida futura.

Se considera la idea de la circularidad como un universal, simboliza la eternidad, sin principio ni fin, la forma circular de las sepulturas puede asociarse con la eternidad; el viaje al otro mundo significaría una nueva etapa de la vida fuera del tiempo real, del presente en que viven las personas, es decir, la relación entre el mundo de abajo y el mundo de arriba.

Otro rasgo relacionado con esta simbología sería la profundidad gradual que a lo largo del tiempo van adquiriendo las sepulturas. Es como si quisieran a través de ésta acercarse al inframundo, colocar a sus difuntos más cerca de los dioses. El agua y los dioses tienen mucha relación. Posteriormente y ya a finales del Periodo de Integración, se vuelve por alguna razón nuevamente a las sepulturas de pozo poco profundo y a los entierros individuales.

La conciencia del paso del tiempo va ligada, al descubrimiento de la autonomía del ser humano y de su destino singular. Es tomar conciencia diferenciada de uno mismo y del grupo, lo que da paso al sentido de la historia y por tanto a la idea de trascendencia que se materializa en la construcción de las sepulturas y en las ceremonias relacionadas con la muerte. La vida de los pueblos agrícolas es circular, todo nace y muere para volver a nacer, el tiempo en sí es circular, los únicos que mueren son las personas, por eso la otra vida es considerada como un renacer a la vida.

La tierra agrícola utilizada para el relleno de las sepulturas simbolizaría la fertilidad, una vez más se vinculan agua y tierra fértil. Posiblemente en el pensamiento religioso de los habitantes de La Florida los muertos sirven de vínculo con los dioses productores de la fertilidad de las personas y de los campos, es por ello que los vivos deben tratar bien a los muertos, esto se traduce en las visitas frecuentes a las sepulturas, y en todo el pensamiento simbólico representado en éstas y en los ajuares y vestimentas rituales. 
En el estudio de los niveles ocupacionales de las sepulturas se apreciaron actividades recurrentes tales como la posición y orientación de los esqueletos que los estaría vinculando a la montaña, como dios protector de vivos y muertos, así la ubicación en sí del yacimiento al pie de la montaña también tendría un sentido ritual.

La posición de los esqueletos sentados en una tianga o sobre esteras los relacionaría con la idea de autoridad. En los relatos tempranos de la Audiencia, las autoridades se sentaban en banquillos, mientras que el resto de las personas lo hacían en el suelo, así pues los muertos como vínculo con los dioses adquirirían autoridad ante los vivos. En general la costumbre de usar banquillos para expresar autoridad no es solo ecuatoriana, aparece en toda la América prehispánica. En las zonas del norte de Sudamérica desde épocas prehispánicas los bancos son vistos como un lugar de comunicación con lo sobrenatural (Guinea, 2004: 12).

Los rituales relacionados con la muerte constituyen el ejemplo más claro de la idea de trascendencia, porque en su doble naturaleza de testimonio y misterio seducen a los seres humanos hacia lo desconocido, la vida de ultratumba. Los ajuares fúnebres son la expresión material de los ritos relacionados con la muerte y una buena ocasión para reunir a la comunidad y fomentar la conciencia de pertenencia a un grupo, así la comunidad logra una mayor cohesión. El mensaje de los diseños realizados en la cerámica y en los objetos rituales en general, proporcionan muchos elementos importantes para entender el pensamiento religioso del grupo.

En las sociedades donde la escritura está ausente el vehículo para la transmisión de ideas y conceptos es la formulación de símbolos convencionales que se plasman a través de la cerámica, orfebrería, huesos, moluscos, etc. y que se materializan en ritos y ceremonias, así los individuos pueden trasmitir su filosofía a las generaciones venideras. Es pues importante analizar los diseños que presentan los objetos de los ajuares y vestimentas fúnebres para desentrañar el pensamiento de los individuos que habitaron nuestro territorio en épocas pasadas. Conjuntamente con ello, los materiales y colores que se utilizan también debieron tener un significado simbólico.

Hay que distinguir entre la vestimenta de los difuntos y el ajuar propiamente dicho, ya que la una puede estar relacionada con la situación social de la persona, mientras que la otra simboliza los ritos correspondientes a las ceremonias fúnebres. La posición del ajuar con relación al difunto puede simbolizar la dualidad izquierda/derecha asociada a los valores de poder, masculinidad o feminidad, etc. Los ajuares de la sepultura 1 que se encuentran frente y a un lado de los individuos ubicados en la plataforma y en la cámara central podría estar expresando la dualidad complementaria entre la vida en el más allá y las ofrendas de los vivos que las comparten con los muertos, así como también los muertos comparten entre sí el ajuar, y estos se vincularían complementariamente con los vivos. En los individuos enterrados en las sepulturas 2 y 4 , la complementariedad se realizaría únicamente entre el difunto y los vivos.

Los materiales usados para la vestimenta de los esqueletos de la cámara central demuestran una clara correlación entre la expansión del intercambio externo y el crecimiento de la organización de la producción dentro de un sistema socio cultural. La presencia de conchas marinas como las cuentas de Spondylus Princeps y calcifer, las plaquetas de madre perla y los caracoles, son indicadores de un comercio a larga distancia, lo que demostraría que la organización social fue compleja.

El empleo de moluscos en la vestimenta ritual, tan difundidos en la Sierra Norte, estarían demostrando no solo el uso de un objeto exótico, sino también la incorporación de éste en el pensamiento religioso. Posiblemente los colores jugarían un papel primordial en la representación de este pensamiento, el rojo de las cuentas de la Spondylus Princeps estaría simbolizando la sangre de la vida y los caracoles prunum de Zapotillo de color verde, se asociarían con la fertilidad, como símbolo del agua. Según Gutiérrez Usillos (2002: 305) el spondylus también estaría simbolizando lo femenino. En el pensamiento dual, simbolizaría el agua de lluvia. Estos símbolos podrían haberse usado en distinta forma según el año, a un periodo de sequía, se imploraría la lluvia, en años con abundantes lluvias se invocaría por el cese de éstas. Dependería del tipo de año en el que murió la persona para usar una simbología u otra. 
Los ganchos de propulsor encontrados en las cámaras centrales de las sepulturas hablan no solo de la zona de origen sino también de la simbología asociada al color y al material. Los ganchos de propulsor son de jaspe, chert, cuarzo, travertino y arcillosita, los tres primeros proceden de Esmeraldas y ríos de la Amazonía y los otros son propios de fuentes de aguas termales. Hay abundantes fuentes termales cercanas al yacimiento y cerca de posibles rutas al noroccidente y hacia la Sierra Norte. Pacto y Niebla en el noroccidente y Selva Alegre en Imbabura son un ejemplo. Las propiedades medicinales de estas aguas posiblemente fueron utilizadas por los pueblos prehispánicos y llegarían a tener connotaciones religiosas, por ello las piedras del lugar pasaron a ocupar un puesto de importancia en los rituales fúnebres. Nuevamente estamos relacionados con el agua y por tanto con la fertilidad, pensamiento recurrente en los rituales de la muerte.

Toda la cerámica procedente de las sepulturas pertenece a la cultura Negativo del Carchi o Capulí, caracterizada por sus diseños en engobe negro sobre engobe rojo, técnica que se consigue combinando diferentes arcillas, el rojo se obtiene con arcillas de bajo contenido de hierro, mientras que en el negro con arcillas de alto contenido de hierro (Romero, 2006), esto además de apuntar hacia la búsqueda de colores simbólicos, denota grandes conocimientos por parte de los ceramistas.

El uso combinado del rojo para el fondo de los recipientes y el negro para los diseños podría simbolizar la dualidad complementaria (Echeverría, 2004: 205), característica propia del pensamiento andino. En este caso al ser una cerámica de origen funerario, podría expresar la complementariedad entre el mundo de abajo con el mundo de arriba. El rojo podría también simbolizar el atardecer, el ocaso de la vida, la muerte, mientras que el negro la noche, el tiempo incierto, el más allá (Milla Euribe, 1990: 27).

Una de las características del pensamiento en la Sierra Norte es el continuo diálogo con la naturaleza que les llevaría a conocer los cambios climáticos a la perfección. El asegurarse las lluvias para obtener la fertilidad de los campos debió ser uno de los elementos importantes del pensamiento religioso. En las sepulturas de pozo profundo y cámara central está presente la idea de la fertilidad, la misma que es recurrente en los diseños de los platos y tinajas de los ajuares funerarios.

Uno de los problemas climáticos de la Sierra son los descensos bruscos de la temperatura que en épocas de sequía se traducen en fuertes heladas que acaban con los sembríos. Este fenómeno se acentúa en los valles, por lo que la ubicación del yacimiento de La Florida en las laderas del Macizo del Pichincha denota un buen conocimiento climático, sus campos de cultivo estarían más resguardados de las heladas. El conocimiento de este fenómeno debió requerir de expertos que conocían bien de astronomía y que conjuntamente con ceremonias propiciatorias procuraron defender sus cultivos de las heladas.

Posiblemente la relación entre el mundo de abajo, o de los muertos, con el mundo de arriba, o de los vivos, debió ser un elemento importante para evitar la quema de los sembríos con las heladas, de ahí las visitas frecuentes a las sepulturas y el sellamiento paulatino de éstas con tierra agrícola. Es como si se les estuviera recordando a los difuntos la necesidad de la fertilidad de los campos. Los diseños en la cerámica de los ajuares fúnebres apuntan constantemente a la relación entre los elementos de la naturaleza y los muertos.

Echeverría Almeida (2004: 172) analizando el pensamiento andino afirma que los cerros eran adorados como fuentes de agua y que en los lugares de culto, conjuntamente con los cerros, veneraban a los antepasados. Este pensamiento podría explicarnos la relación que existe tanto en la ubicación de las sepulturas como en la orientación de los difuntos hacia el Macizo del Pichincha, así mismo estaría en concordancia con el diálogo establecido entre el mundo de arriba y el mundo de abajo.

Los diseños cerámicos incluyen el triángulo escalerado como reflejo de la montaña o también como la base del poder (Guinea, 2004: 16), el poder de la montaña para proteger a los vivos y a los muertos (fig. 2). 


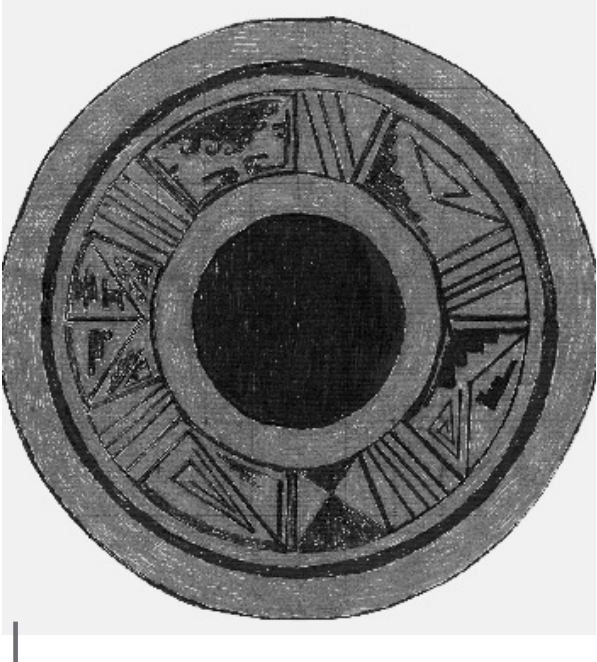

Figura 2 - Triángulo Escalerado
Echeverría Almeida (2004: 172), citando a Giese (1991), afirma que la serpiente es uno de los animales relacionados con la custodia del agua. La representación de serpientes en los diseños de los platos es muy frecuente, podría asumirse que simbolizan este pensamiento, pero también se las puede asociar como animales que salen del mundo de abajo hacia el mundo de arriba para conectar estos dos espacios religiosos. En uno de los platos procedentes del ajuar de la sepultura 1, se representa una serpiente en bajo relieve reptando hacia el borde del mismo, como si saliera del inframundo hacia el mundo de los vivos (fig. 3). Otros platos y vasijas también incluyen recurrentemente en sus diseños serpientes esquematizadas; sería pues un reptil simbólico que representaría la unión de los dos mundos y por qué no, también la fertilidad.

La representación de serpientes en los platos de la cultura Negativo del Carchi llega a una simplificación abstracta que muchas veces sustituye a la figura, se convierten en líneas oblicuas que no solo representan a los animales sino la unión de los dos mundos, el de arriba y el de abajo formando triángulos isósceles. Este tipo de representación es característico de la cerámica Negativo del Carchi o Capulí, creando una uniformidad en toda la región que, al decir de Gutiérrez (2002: 302), no se puede entender sino como una difusión de una creencia en concreto que llega a homogenizar el pensamiento.

Los reptiles, y en particular las serpientes, también significan renovación, vida y muerte, el cambio periódico de la piel se convierte en un símbolo del renacer. La muerte es pues un renacer a otra vida en el más allá. Entre los restos de alimentación recuperados al interior de las vasijas de los ajuares identificamos ciervos, conejos y roedores, su presencia denotaría el consumo ritual de animales cazados en el páramo cercano. La caza debió ser una actividad solamente colectiva de personas especializadas.

En otros yacimientos de la Meseta de Quito, y en general en la Sierra Norte, también se han encontrado restos de animales ya sea como desechos en los basureros o como parte de los ajuares funerarios, unos al interior de vasijas y otros elaborados, como las espátulas que portaba en sus manos uno de los individuos de la cámara central de la sepultura 1. Doyon (1989: 192) recuperó una flauta hecha con huesos de venado de una de las sepulturas contiguas a las nuestras. El venado no solo fue parte de la comida en las ceremonias fúnebres sino que también debió tener en la Sierra Norte connotaciones simbólicas. Es frecuente encontrar representaciones de venado en los platos Cuasmal, identificadas por Gutiérrez (2002: 171) como de la especie de cola blanca. En nuestro caso desgraciadamente no se pudo identificar la especie.

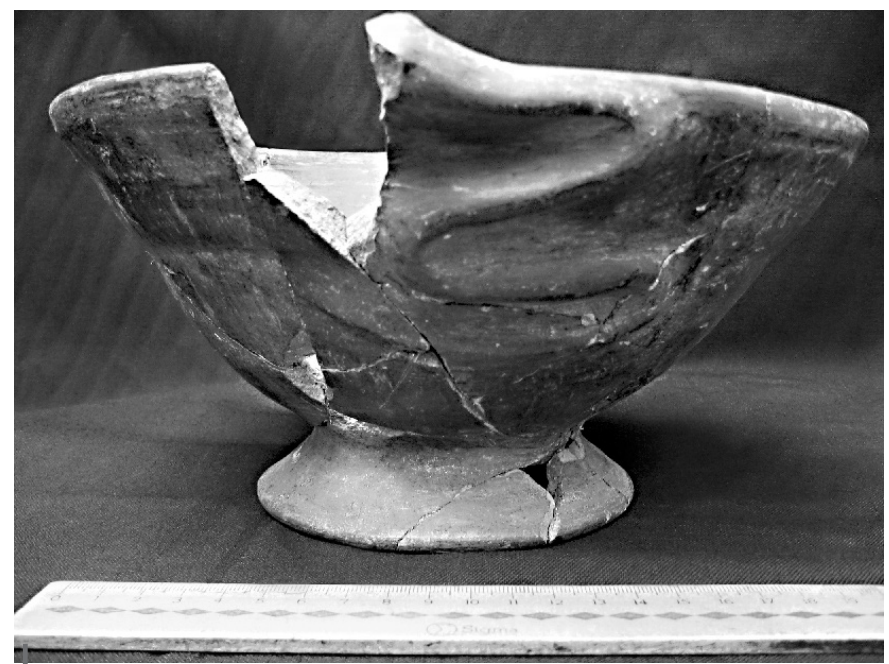

Figura 3 - Sepultura 1: plato 
Las representaciones de aves en los platos de los ajuares de la sepultura 1 y una avecilla que sujetaba uno de los individuos de la cámara central de la sepultura 2 podría estar relacionada con la divinidad. En general los pueblos en el mundo entero han visto en las aves poderes sobrenaturales, su capacidad de volar y ver el mundo desde arriba es un atributo divino, de ahí que suelan vincularlas con lo sobrenatural. La muerte pues sería un vínculo con la divinidad. Es elocuente la representación de un pájaro en un plato de la sepultura 1, se halla en actitud de volar como si uniera los cielos con la tierra. Existen innumerables leyendas y creencias en todos los pueblos del continente americano relacionadas con las aves.

La representación del mono es sistemática en la Sierra Norte, parece que fue un símbolo muy importante, desgraciadamente es difícil desentrañar todo su significado. Su presencia no es exclusiva de nuestra zona, en las culturas de la costa se le encuentra en morteros de piedra que posiblemente sirvieron para preparar medicinas o alucinógenos.

El mono por su parecido físico con las personas ha sido representado en muchos lugares del planeta y siempre ha tenido un lugar predominante en las filosofías de los pueblos. Nosotros lo encontramos en dos prendedores de oro que sujetaban la mortaja de dos individuos en la cámara central, su técnica es el laminado y recortado con soldadura para el alfiler (fig. 4).

La representación de monos en el Ecuador es muy temprana, en Valdivia aparece junto con el felino y el guacamayo formando una triada del bosque tropical y en relación con los alucinógenos (Gutiérrez, 2002: 318). En América en general, es frecuente encontrar a los primates asociados con el caracol marino. En los caracoles de cerámica del Carchi se lo encuentra ya sea formando parte del conjunto o bien como un diseño en su interior (Molestina Zaldumbide, 1998: 245). En la Sierra Norte, y especialmente en el Carchi y Nariño, es donde con mayor frecuencia es representado durante el Periodo de Integración. Uno de estos prendedores se encontró como parte de la vestimenta ritual de un individuo que llevaba en los extremos del traje caracoles a manera de ribetes, el mono en este caso estaría simbólicamente asociado a los caracoles. Algunos investigadores lo consideran portador de las lluvias y de la fertilidad, pero también se lo ha asociado a la sabiduría (Erazo Rodríguez, 2004). En todo caso a estos primates se los debió conocer en la sierra a través del comercio con la Amazonía. Antonio de Borja (1992 [1591]: 481) anota que los quijos traían monos a Pimampiro para intercambiarlos por coca, sal y otros productos.

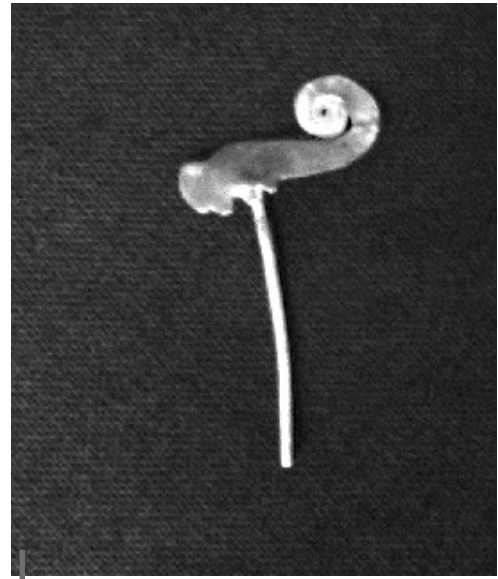

Figura 4 - Sepultura 2: prendedor de oro

A los primates también se les asocia con el viento por lo que pueden predecir la estación de las lluvias, esencial para el inicio de las siembras. Poseerían el conocimiento que los igualaría a los seres humanos; el mono pues se convertiría en símbolo de algunos elementos necesarios para las personas. Posiblemente también tuvo un carácter divino.

En todas las representaciones funerarias de nuestras sepulturas se puede apreciar una concepción del universo en el que prima la relación cultivos/agua/fertilidad, frente a la caza/ fertilidad. Hay algunos diseños cerámicos en los que se representa la lluvia, los campos de cultivo y los vientos, elementos asociados al ajuar funerario y estarían hablando de que la muerte fue una ocasión de combinar los rituales fúnebres con los de propiciación para la fertilidad de las personas y de los campos. El espacio físico que ocupa la necrópolis se convierte en una zona sagrada que posiblemente fue considerada como el centro del mundo, el espacio de encuentro con los dioses y los antepasados; sería el lugar que asegura la continuidad de la vida de toda la comunidad. Por ello los rituales relacionados con la muerte tienen un fuerte componente simbólico relacionado con la fertilidad.

La muerte sería pues concebida como una regeneración, un nuevo nacimiento. La construcción de las sepulturas sería el comienzo hacia una nueva vida, una especie de regeneración 
o purificación en esta vida que les prepararía para la otra vida. Para Eliade (2004: 21), toda construcción es un comienzo absoluto que tiende a restaurar el instante inicial, es decir el origen de los individuos y de la comunidad, así la necrópolis podría haber significado el sitio de origen por yacer allí los antepasados, y a la vez el inicio de una nueva vida.

La forma en sí de las sepulturas de pozo profundo con cámara central estaría materializando el origen, la cámara central representaría este concepto; los individuos enterrados en ella debían engalanarse, a diferencia de lo que sucede con los enterrados en la plataforma que utilizan vestuarios de la vida cotidiana. En la sepultura 4, únicamente un individuo estaba ataviado con spondylus, prendedores de oro y ganchos de propulsor, el resto debió tener una vestimenta sencilla, el individuo engalanado de esta manera fue el primero en enterrarse, por lo que representaría el origen.

Los objetos de orfebrería no pueden quedar fuera de la simbología fúnebre. Se encuentran siempre formando parte del ajuar de los individuos enterrados en la cámara central, por lo que su mensaje estaría relacionado con el origen de la comunidad. Los objetos encontrados por lo general no presentan decoración, su técnica es el laminado y recortado, unos son de oro; otros de cobre y de cobre dorado, estos últimos realizados con la técnica de fusión. A excepción de las láminas tubulares de oro, el resto de objetos forman parte de la vestimenta ritual de los individuos.

Los discos de oro, cobre y cobre dorado van cocidos a la vestimenta, mientras que los prendedores de oro y cobre sujetan parte de ésta. Los cascabeles de cobre forman parte del remate de las vestimentas. Los pectorales son de cobre dorado y cobre, y en un solo individuo encontramos una nariguera doble. Tenemos un solo ejemplo de un disco de oro encontrado en la mortaja de uno de los individuos de la sepultura 2 en el que se ha realizado un diseño con la técnica del repujado.

Similares a las cuentas hechas de Spondylus tenemos cuentecillas de cobre con algún componente de oro en la superficie que forman parte de la vestimenta ritual. Los objetos de oro procedentes de la sepultura 1 presentan una aleación de oro, plata y cobre; las proporciones de oro en el caso de las piezas decorativas son mayores que en las utilitarias donde predomina el cobre. La suelda de oro se hizo con la técnica de fusión. De esta forma la suelda caliente no disuelve la superficie del objeto a soldarse sino que se adhiere al mismo. Por lo general el oro de los objetos decorativos es de 22 quilates mientras que el de los utilitarios, por su mayor contenido de cobre es de 19 quilates. En los de las sepulturas 2 y 4 se ha utilizado un promedio de oro de 21 quilates, el procedimiento empleado en las sueldas es el mismo que para los de la Sepultura 1. En estos objetos no existe relación entre el contenido de oro y su aplicación.

El oro y el cobre podrían haber sido trabajados en el mismo yacimiento. Los estudios geológicos efectuados en la zona han detectado oro aluvial y pirita en las quebradas cercanas que bajan del Macizo del Pichincha (Sandoval, com. pers.). Solorzano en las excavaciones realizadas en La Florida encontró un crisol que en su interior contenía restos de oro y cobre fundido. Como parte del ajuar de la sepultura 3 encontramos una toba volcánica que se comporta de una forma similar a la arcilla y que había sido modelada para darle una forma cónica (fig. 5), presentó restos muy pequeños de láminas de oro, lo que nos sugiere que pudo haber sido utilizada a manera de molde para dar forma a los objetos.

La presencia de tobas volcánicas cónicas no es única de La Florida, se las ha reportado como parte de los ajuares funerarios en Cayambe (Molestina Zaldumbide, 1985: 79) y Cochasquí (Zalles Flossbach, 1981: 81) este último sugiere que posiblemente sirvieron como apoyos o moldes para la confección de objetos de láminas de metal precioso o para cualquier otra tarea de los orfebres.

La evidencia más antigua del trabajo en oro en el Ecuador es la de Putushio, en la sierra sur, el yacimiento perteneciente al Formativo tardío y está datado en torno a 1470 a.C. (Temme, 2000: 125). Los objetos se habían trabajado en base al martillado y recortado. Para la Meseta de Quito, los hallazgos de Cumbayá (200 a.C.) serían los más antiguos. En el mismo yacimiento y procedentes de las sepulturas tanto del Desarrollo Regional como de Integración se 


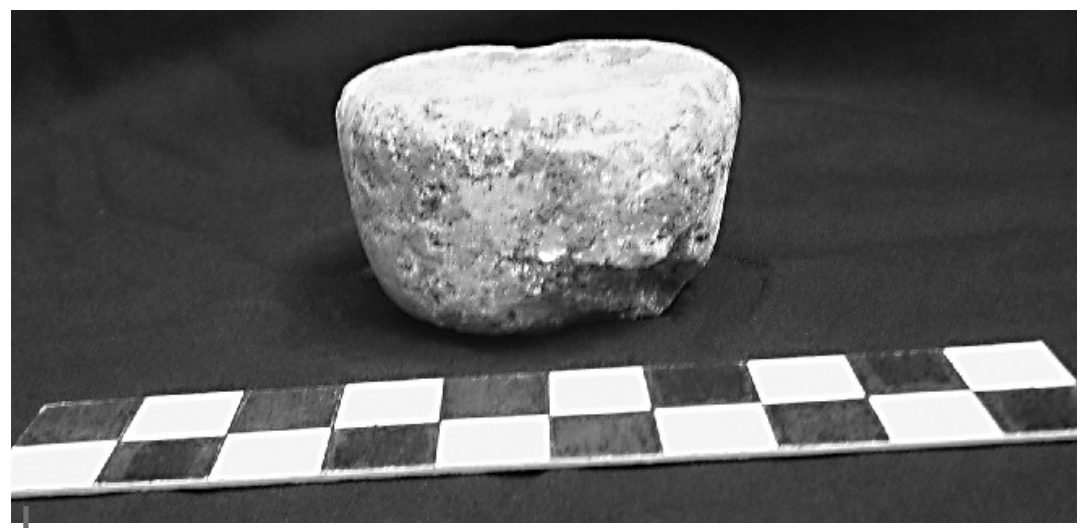

Figura 5 - Toba modelada

encontraron varios objetos de cobre y oro que integraban la vestimenta de diferentes individuos. Se trata de discos laminados y repujados, y un tinculpa de cobre (Buys et al., 1994: 95). En otros yacimientos de Integración tardío como Chilibulo y Chillogallo también la orfebrería en oro y cobre estuvo presente como parte de la vestimenta de los difuntos.

Jijón y Caamaño (1920: 4) reporta para Alchipichi y Pomasqui, los dos en la Meseta de Quito, tinculpas de cobre con decoración de felinos repujados. Estas representaciones son frecuentes en la orfebrería de la Sierra Norte. Objetos similares a los nuestros se reportan para el departamento de Nariño (Lleras Pérez et al., 2002: 4-6) con dataciones en unos casos contemporáneas a las nuestras y en otros posteriores. Las piezas de Nariño analizadas por Plazas (1977-1978: 198) tienen la misma aleación que las nuestras, parecería que se trata de una técnica similar que podría haberse esparcido desde La Florida hacia el norte.

En Atacames se recuperaron una serie de objetos de cobre, oro y cobre dorado, así como instrumentos para el trabajo en metales. Guinea (1998: 84-87) propone que el metal fue trasladado en láminas desde el norte del Perú e intercambiado por Spondylus; nosotros creemos que por la composición del cobre de Atacames similar al de La Florida, su origen bien pudo ser nuestro yacimiento.

En el Ecuador prehispánico la orfebrería se extendió tanto en la sierra como en la costa y Amazonía. Varios cronistas describen la decoración simbólica de las embarcaciones con objetos de oro. En la zona de Coaque, provincia de Manabí, Miguel de Estete (citado en Marcos, 2005: 44) afirma que encontraron al interior de las casas objetos de oro, plata y esmeraldas. Cieza de León (1553, en Marcos, 2005: 45) narra que los indios de Puerto Viejo adornan sus personas con joyas de oro combinadas con cuentas de Spondylus princeps, así mismo los comerciantes cambian gran cantidad de oro por las cuentas de Spondylus por lo que no nos extrañaría que en La Florida se dedicaran al trabajo en metales a fin de intercambiarlo con cuentas de spondylus, necesarias para sus ceremonias. El Anónimo de 1573 afirma algo parecido para los indígenas de la región de Quito.

Las fuentes de oro son originarias de las cordilleras Oriental y Occidental, en las quebradas y ríos se recolecta oro aluvial así como piritas y calcopiritas que en el lenguaje popular se denomina oro tierno. En Sarapullo al pie del Corazón, hay yacimientos polimetálicos. Posiblemente ya desde la época prehispánica se recolectó estos metales y continuó durante la Audiencia. Otros lugares cerca de nuestro yacimiento son Lloa y Lumbisí, incluso en Lloa existe la leyenda de «La cueva del padre encantado» que queda entre el Guagua y Ruco Pichincha. Se cuenta que un hombre entraba y salía, después de algunos días cargado con un costalillo, realizó varios viajes y luego se fue a vivir en la ciudad de San Francisco de Quito con todas las comodidades, la gente dice que su fortuna la sacó de la cueva. 
Los cronistas del siglo XVI y los documentos tempranos registran el uso por parte de los indígenas de la costa del oro como adorno personal y las esmeraldas engastadas en los objetos de orfebrería como narigueras, orejeras, etc. La Emperatriz Isabel en 1536 (Navarro, 1986: 6) mandó a comprar para ella y el Emperador las mejores esmeraldas que producía la Audiencia de Quito. Actualmente Colombia es uno de los productores mundiales de esmeraldas.

A pesar de la abundante referencia a las minas en todo el territorio de la Audiencia de Quito, en los documentos no se precisa el lugar y parece que no se las explotó, pues no se trataba de verdaderas minas sino de oro aluvial de ríos y quebradas. Antonio de Borja en 1591 cita la existencia en Mira, actual provincia del Carchi en la Sierra Norte del Ecuador, de una quebrada llamada Quique que arrastra oro y plata y de la que se benefician los indios.

En las actas del Cabildo de la ciudad de San Francisco de Quito se hacen muchas referencias a la explotación del oro por parte de sus vecinos, incluso llegan a nombrar un alcalde de minas y ensayador. De acuerdo al testimonio de Alonso Camacho, minero, hecho en 1548 al Cabildo de la Ciudad, las minas se encuentran en los términos de la misma.

Las ordenanzas relativas a la explotación de minería establecían se realizara esta actividad durante el verano, es decir a partir del mes de junio y más concretamente del 24 de junio, fiesta de San Juan, lo que certificaría que se trata de oro aluvial que bajaba por ríos y quebradas: al disminuir las lluvias en verano, lavar el oro era más fácil. Seguramente en el periodo prehispánico también se utilizó la estación seca para estos menesteres.

Salazar de Villasante (1992 [1570]: 85) al hablar de la ciudad de San Francisco de Quito dice que aunque no se han encontrado minas de oro, los arroyos que provienen del Pichincha llegan cargados de pepitas de oro y que los indios las recogen, indica además que hacia el pueblo de Pintac, cerca de la ciudad, se encontraron huellas de que se trabajaba el oro. No nos llame pues la atención que en los yacimientos prehispánicos de la Meseta de Quito se encuentren objetos trabajados en este metal, llegando sus orfebres a una alta especialización. Benzoni, platero natural de Milán Italia, refiere que:

«los indios cuando funden el oro y la plata colocan el metal en un crisol largo o redondo, hecho de un pedazo de trapo embadurnado con tierra mojada y carbón machacado, una vez que éste está seco lo ponen al fuego con la cantidad de metal que puede caber en él. Con cinco o seis canutos de caña, ora más ora menos, tanto soplan que éste termina por fundirse u colar. Luego sentados los orfebres en el suelo, con unas piedras negras confeccionadas para esta clase de labor, ayudándose uno al otro, hacen, o por mejor decir hacían, en la época de su prosperidad, lo que se había mandado confeccionar, esto es estatuas vacías, vasos, ovejas, joyas y en fin, toda suerte de figuras de los animales que se podían ver». (Navarro, 1986: 54)

Existen pocas referencias documentales sobre el cobre, seguramente porque solo fue utilizado en la Audiencia esporádicamente para la fabricación de moneda menuda y en general para objetos utilitarios comunes.

Jijón y Caamaño (1920: 37) establece para Sudamérica dos zonas cupríferas: Colombia, Ecuador y Perú, en las que el cobre no presenta impurezas de estaño y Bolivia, Argentina y Chile cuyo cobre presenta estaño como impureza. División interesante que habría que profundizar para identificar el origen y difusión de los objetos prehispánicos.

Los metales trabajados en La Florida podrían representar una simbología en cuanto al color. El amarillo del oro por lo general ha sido asociado con el amanecer, y podría estar relacionado con el inicio de un nuevo día, de una nueva vida en ultratumba. Mientras que el cobre por su color oscuro podría significar el ocaso, es decir el final de la vida terrestre. Al proceder todos los objetos metálicos de ajuares y vestimenta funeraria, debemos limitarnos al pensamiento fúnebre. La forma circular de las cabezas de los prendedores nos está nuevamente sugiriendo la circularidad, lo infinito, el mundo sin tiempo del más allá (fig. 6). Procedentes de las sepulturas 2 y 4 tenemos prendedores que posiblemente representen la sepultura de pozo profundo y cámara central, interpretando la cámara central como el símbolo del origen o raíz (fig. 7). 


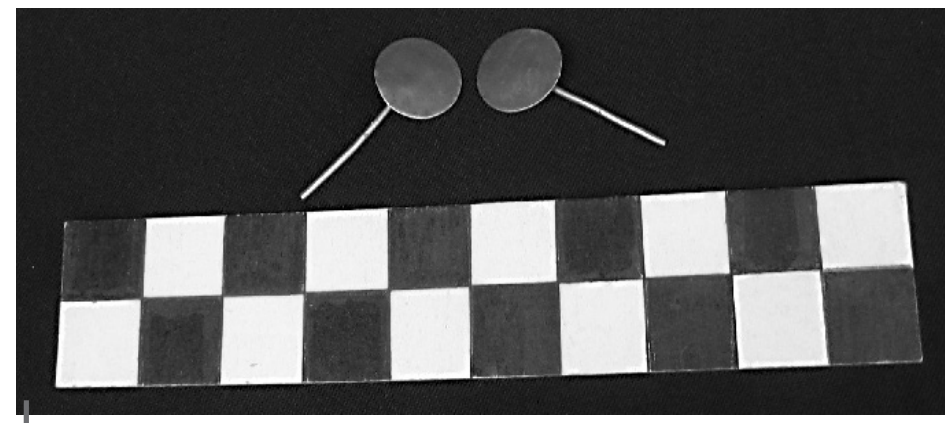

Figura 6 - Sepultura 2: prendedores

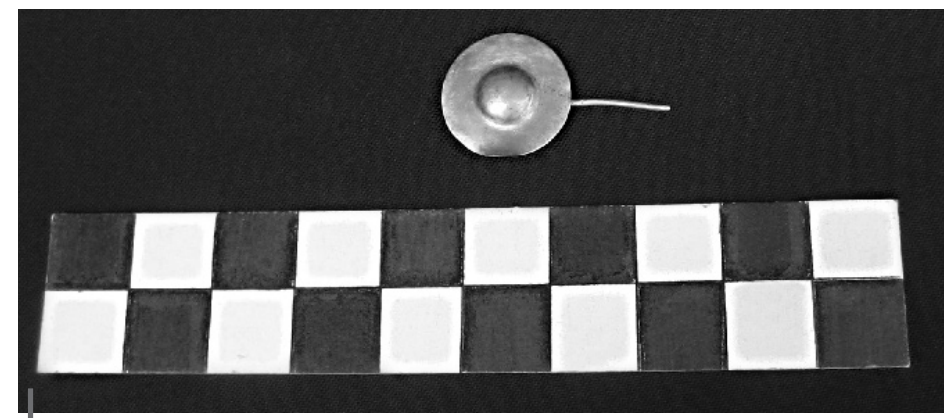

Figura 7 - Sepultura 2: prendedor

\section{CONCLUSIONES}

Cuando León Doyon en 1989 realiza las excavaciones de las sepulturas de pozo profundo y cámara central en La Florida llega a la conclusión de que se trataba de enterramientos de personajes de la elite quiteña que en sus rituales sacrificaba a una serie de personas para que les acompañaran en el viaje al más allá. Hasta este momento, ninguno de los investigadores que había excavado este tipo de sepulturas en la Sierra Norte había propuesto tales rituales. Posteriores investigaciones en La Florida cuestionan la cronología de Doyon, mas no sus conclusiones.

El resultado de nuestras excavaciones en las sepulturas contiguas a las excavadas por Doyon llega a una evidencia completamente diferente, se trata de enterramientos múltiples que obedecen a un pensamiento simbólico plasmado tanto en los ajuares como en la construcción de las sepulturas. Las personas no fueron enterradas simultáneamente. Se hizo conforme se iban muriendo, y en las sepulturas 2 y 4 los ajuares son individuales.

El análisis de los materiales producto de las excavaciones se ha centrado por lo general en las formas cerámicas y en la descripción de otros materiales excavados, esto es importante, sin embargo, es necesario ir más allá hacia una interpretación del objetivo para el cual se realizaron esos objetos.

La necrópolis de La Florida es un lugar sagrado destinado a celebrar la vida y la muerte. Es el espacio en el que se une el presente con el más allá a través de los difuntos. Todo en las sepulturas nos habla de la relación de los vivos con los muertos y de éstos con los dioses en el otro mundo. El mundo de aquí y el del más allá están interrelacionados, no hay uno sin el otro, no hay vida sin muerte.

El pensamiento fúnebre prioriza la idea de la fertilidad, el origen y la unión de los vivos con los muertos — vínculo entre la divinidad y el mundo de aquí, del presente-. 
Los símbolos recurrentes en los diseños cerámicos son la serpiente, la lluvia, el viento, los campos de cultivo, escaleras, rayos, círculos y triángulos isósceles, todos ellos relacionados con la naturaleza, la fertilidad y la dualidad complementaria. Los colores rojo y negro como símbolos de la vida y la muerte — característicos de los diseños cerámicos funerarios - refuerza esta simbología religiosa.

Los habitantes de La Florida poseyeron un entorno privilegiado para desarrollar sus actividades religiosas y cotidianas. La montaña fue no solo un recurso para la cacería, leña y maderera, sino también un elemento simbólico importante. Las quebradas proporcionaron la materia prima para la orfebrería, agua para bebida y regadío y posiblemente durante la estación seca fueron utilizadas como caminos para el intercambio de productos.

La cercanía a la laguna de Iñaquito debió proporcionar además de la hematites (¿̇?) para sus rituales funerarios, caza y pesca como un recurso proteínico importante. En una de las vasijas procedentes de la sepultura 2 se analizó restos de pescado mezclados con otros alimentos como el maíz y los chochos. La totora sería una fuente de materia prima para la elaboración de esteras y cestería. Posiblemente los camellones registrados por Villalba \& Alvarado (1998: 74) fueron utilizados durante la temporada seca para el cultivo del maíz, papas, frijoles, etc.

El comercio proporcionó además de productos necesarios para la vida diaria, objetos exóticos fundamentales para los rituales y posiblemente para la afirmación de estatus en una sociedad jerarquizada.

La presencia de las conchas y ganchos de propulsor afirman la existencia de un comercio con la costa y amazonía que debió llevarse a cabo en base a una red de mercaderes que llevarían los productos a intercambiarse a lugares previamente señalados, que no debieron estar muy lejos del yacimiento. La existencia de petroglifos localizados ya sea hacia el noroccidente y la amazonía podría señalar lugares de encuentro y a la vez constituirse en espacios simbólicos de contacto religioso. Debieron existir divinidades protectoras de los comerciantes que seguramente fueron invocadas al salir, durante el trayecto y al regreso del viaje, para ello tendrían ceremonias propiciatorias específicas.

Dada la cantidad de idiomas que se hablaba en las distintas regiones de la Sierra Norte (Paz Ponce de León, 1965 [1582]: 235) se procuraría una simbología común que se plasmaría en los petroglifos y que pueda representar a los dioses protectores del comerciante. Antonio de Borja (1591: 486) al hablar de las creencias de los indígenas de Pimampiro dice que éstos se encomiendan al «demonio» antes de salir de viaje ofreciéndole sacrificios a los dioses.

La evidencia del comercio de la coca solo se ha podido rescatar en la sepultura 1, lo que no quiere decir que su uso fue esporádico, posiblemente fue uno de los productos a intercambiarse con los pueblos de la zona de Pimampiro. Existen vasijas pequeñas procedentes de la sepultura 4 que posiblemente se usaron como recipientes destinados a contener coca. Otro indicador del uso de la coca es un lliptero encontrado como parte del ajuar de la sepultura 3, que si bien es muy posterior a las de pozo profundo y cámara central, puede evidenciar el uso continuado de la coca, costumbre que se registra en los documentos tempranos de la Audiencia de Quito.

Por la abundancia de objetos exóticos depositados en las sepulturas los habitantes de La Florida consideraron al comercio como una actividad prioritaria. Debieron existir otros bienes de importación que no los hemos podido registrar dado el limitado contexto de investigación. A más de los metales existirían otros bienes apetecidos por los diferentes grupos de contacto que se incluirían en la lista de objetos para ser intercambiados.

No podemos establecer por el momento una jerarquía manifiesta en los enterramientos, parece que las personas eran enterradas indistintamente; sin embargo no descartamos la posibilidad de que existan sepulturas especiales para los caciques y shamanes. Por la tecnología empleada en las sepulturas la sociedad de La Florida fue muy organizada y posiblemente jerárquica, seguramente estuvo al mando de un cacique encargado no solo de organizar el trabajo sino también de la producción de excedentes para el intercambio. 
La evidencia de un pensamiento fúnebre complejo y rituales que materialicen el mismo demuestra que existió un grupo de yachacuna capaz de organizar el trabajo y los rituales. Estos serían los intermediarios entre los vivos y los muertos, y encabezarían las frecuentes visitas a las sepulturas y los ritos al interior de las mismas.

La forma en sí de las sepulturas demuestra un manejo de la geometría y la tecnología adecuada para el trabajo en cangahua, reflejo de una sociedad experta en el conocimiento arquitectónico.

La interpretación simbólica del círculo, plataforma y cámara central como elementos recurrentes en todas las sepulturas nos hablan del origen, de la unión entre el mundo de arriba y el de abajo (Erazo Rodríguez, 2006: 4), pensamiento que se repite en los elementos que componen el ajuar funerario y la vestimenta ritual.

En resumen se trata de enterramientos del Periodo de Integración pertenecientes a la cultura Negativo del Carchi o Capulí que comparten las manifestaciones culturales con la Sierra Norte Ecuatoriana. Desde el punto de vista cronológico, La Florida sería por el momento el yacimiento más antiguo de este periodo y su influencia cultural se expandiría hacia el norte hasta llegar al departamento de Nariño en Colombia.

\section{Referencias citadas}

ALVARADO CEVALLOS, A. P., 1996 - Evolución Geológica cuaternaria y paleosismicidad de la Cuenca de Quito-Ecuador, 300 p.; Quito: Escuela Politécnica Nacional. Tesis presentada a la Facultad de Geología, Minas y Petróleos.

ANÓNIMO, 1992 [1573] - Descripción de la ciudad de San Francisco de Quito. In: Relaciones Histórico Geográficas de la Audiencia de Quito (Ponce Leiva, P., ed.): 187-223; Quito: Abya Yala.

BORJA, A., 1992 [1591] - Relación en suma de la doctrina y beneficio de Pimampiro y de las cosas notables que en ella hay, de la cual es beneficiado el padre Antonio Borja. In: Relaciones Histórico Geográficas de la Audiencia de Quito (Ponce Leiva, P., ed.): 480-488; Quito: Abya Yala.

BUYS, J., CAMINO, B. \& SANTAMARÍA, A., 1994 - La investigación arqueológica de Cumbayá, 48 p.; Quito: Proyecto de Cooperación Técnica Ecuabel. Informe Final entregado al Instituto Nacional de Patrimonio Cultural.

CAMINO, B. \& CASTILLO, A., 1997 - Proyecto de salvamento Arqueológico La Florida; Quito. Informe al Instituto Nacional de Patrimonio Cultural.

CAÑADAS CRUZ, L., 1980 - El Mapa Bioclimático y Ecológico del Ecuador, 210 p.; Quito: Banco Central del Ecuador.

DOYON, L., 1989 - A High-Status Cementery of the Regional Developmental Period: Excavations at La Florida (Quito, Pichincha), 260 p.; Quito. Final Report to the Museo del Banco Central del Ecuador.

ECHEVERRÍA ALMEIDA, J., 2004 - Las sociedades prehispánicas de la Sierra Norte del Ecuador, una aproximación arqueológica y antropológica, 378 p.; Otavalo: ed. Instituto Otavaleño de Antropología.

ELIADE, M., 2004 - El mito del eterno retorno, 174 p.; Madrid: ed. Alianza Editorial.

ERAZO RODRÍGUEZ, R., 2004 - Ensayo semiótico del diseño prehispánico quiteño, 20 p. Informe al Proyecto Arqueológico La Florida. 
ERAZO RODRÍGUEZ, R., 2006 - Estudio del diseño prehispánico Quiteño (V d.C.), 10 p. Informe al Proyecto Arqueológico La Florida.

GRIJALVA, C. E., 1937 - La Protohistoria de Imbabura y Carchi, 294 p.; Quito: ed. Chimborazo.

GUINEA, M., 1998 - La Metalurgia del Cobre en la costa norte del Ecuador durante el periodo de Integración. In: El Área Septentrional Andina, Arqueología y etnohistoria (Guinea, M., ed.): 83-110; Quito: Abya Yala.

GUINEA, M., 2004 - Los Símbolos del Poder o el Poder de los Símbolos. In: Simbolismo y ritual en los Andes Septentrionales (Guinea, M., ed.): 9-49; Quito: Abya Yala.

GUTIÉRREZ USILLOS, A., 2002 - Dioses, símbolos y alimentación en los Andes, 473 p.; Quito: Abya Yala.

INSTITUTO GEOGRÁFICO MILITAR (IGM), 1992 - Atlas infográfico de Quito: socio-dinámica del espacio y política urbana/ Atlas infographique de Quito: socio-dynamique de I'espace et politique urbaine, 41 láminas bilingües (español, francés), 29,7cm x $42 \mathrm{~cm}$, 297 p.; Quito: Instituto Panamericano de Geografía e Historia Sección Nacional del Ecuador (IPGH); Institut français de recherche scientifique pour le développement en coopération (Orstom).

JIJÓN Y CAAMAÑO, J., 1920 - Notas Acerca de la Metalurgia de los Aborígenes del Ecuador. Boletín de la Academia Nacional de Historia, 1 (1): 5; Quito.

KNAPP, G., \& RYDER, R., 1985 - Aspectos del origen, morfología y función de los camellones en el altiplano de Quito. Revista Cultura, 23: 206; Quito: ed. Banco Central del Ecuador.

LARREA, C. M., 1972 - Prehistoria de la región andina del Ecuador, 207 p.; Quito: ed. Corporación de Estudios y Publicaciones.

LEÓN, P., 2004-2005 - Análisis óseos de las sepulturas de La Florida, 10 p. Informe a Fondo de Salvamento del Patrimonio Cultural del Distrito Metropolitano de Quito.

LLERAS PÉREZ, R., RESTREPO, R. \& GÓMEZ, L. A., 2002 - El tiempo en Nariño y Carchi: Un análisis de la cronología a la luz de nuevos datos. In: Seminario Pasado y Presente en la Arqueología de Nariño y Carchi: 1-29; Pasto: Banco de la República.

MARCOS, J., 2005 - Los pueblos Navegantes del Ecuador Prehispánico, 206 p.; Quito: Abya Yala.

MILLA EURIBE, Z., 1990 - Introducción a la semiótica del diseño andino precolombino, 92 p.; Lima: ed. Concytec.

MIÑO GRIJALVA, M., 1977 - Algunos problemas arqueológicos en la Sierra Norte del Ecuador: Carchi. In: Estudios Arqueológicos. Antillas y Tierras Bajas de Sudamérica (Meggers, B. J. et al., eds.): 161-180; Quito: Pontificia Universidad Católica del Ecuador.

MOLESTINA ZALDUMBIDE, M. del C., 1985 - Investigaciones Arqueológicas en la zona Negativo del Carchi o Capulí. Revista Cultura, 21: 79; Quito: ed. Banco Central del Ecuador.

MOLESTINA ZALDUMBIDE, M. del C., 1998 - Transferencias ideológicas en la Sierra Norte (Ecuador). In: El Área Septentrional Andina, Arqueología y etnohistoria (Guinea, M., ed.): 235-255; Quito: Abya Yala.

NAVARRO, M., 1986 - Investigación histórica de la minería en el Ecuador, t. I, s. XVI-XVII; Quito: ed. Imprenta del Ministerio de Energía y Minas.

OBEREM, U., 1981 - Cochasquí. Estudios Arqueológicos, 3-5: 128; Otavalo: ed. Instituto Otavaleño de Antropología.

PONCE DE LEÓN, P., 1965 [1582] - Relación y Descripción de los Pueblos de Otavalo. In: Relaciones Geográficas de Indias-Perú (Jiménez de La Espada, M., ed.): 235; Madrid: Biblioteca de Autores Españoles.

PLAZAS, C., 1977-1978 - Orfebrería prehispánica del Altiplano Nariñense (Colombia, Bogotá). Revista Colombiana de Antropología, XXI: 197-244; Bogotá.

RODRÍGUEZ DE AGUAYO, 1571 - Descripción de la ciudad de Quito. In: Relaciones Histórico Geográficas de la Audiencia de Quito (Ponce Leiva, P., ed.): 117-122; Quito: Abya Yala. 
ROMERO, M., 2006 - Informe sobre el análisis del contenido de varias vasijas procedentes de la sepultura 2 del Yacimiento de La Florida, 2 p.; Quito.

SALAZAR DE VILLASANTE 1992 [1570] - Relación de la ciudad y provincia de Quito. In: Relaciones Histórico Geográficas de la Audiencia de Quito (Ponce Leiva, P., ed.): 71-83; Quito: Abya Yala.

SOLORZANO, M. S., 2004 - Monitoreo arqueológico de La Florida, Terrana I, 30 p.; Quito. Informe al Instituto Nacional de Patrimonio Cultural.

TEMME, M., 2000 - El Formativo en Putushio, Sierra Sur del Ecuador. In: El Formativo Sudamericano (Lederguerber-Crespo, P., ed.): 124-138; Quito: Abya Yala.

TERÁN, P., 1985 - Los canales de La Florida, 20 p.; Quito. Inédito.

UHLE, M., 1928 - Las Ruinas de Cuasmal. Anales de la Universidad Central, vol. XXXVII (257): 167-177; Quito.

URIBE, M. V., 1977-1978 - Asentamientos prehispánicos en el Altiplano de Ipiales (Colombia). Revista Colombiana de Antropología, XXI: 57-195; Bogotá.

VILLALBA, M., 1988 - Cotocollao, 553 p.; Banco Central del Ecuador, Quito.

VILLALBA, M. \& ALVARADO, A., 1998 - La Arqueología del valle de Quito en clave volcánica. In: Actividad volcánica y pueblos precolombinos en el Ecuador (Mothes, P., ed.): 74; Quito: Abya Yala.

ZALLES FLOSSBACH, C., 1981 - Los artefactos líticos. In: Cochasqui (Oberem, U., ed.), vol. 2: 11-149; Otavalo: ed. Instituto Otavaleño de Antropología. 